\title{
Nobel Lecture: Sand from centuries past: Send future voices fast*
}

\author{
Charles K. Kao \\ (Published 13 August 2010) \\ DOI: $10.1103 /$ RevModPhys.82.2299
}

\section{INTRODUCTION}

It is sad that my husband, Professor Charles Kao, is unable to give this lecture to you himself. As the person closest to him, I stand before you to honor him and to speak for him. He is very, very proud of his achievements for which the Nobel Foundation honors him. As are we all!

In the 43 years since his seminal paper of 1966 that gave birth to the ubiquitous glass fiber cables of today, the world of telephony has changed vastly. It is due to Professor Kao's persistence in the face of skepticism that this revolution has occurred.

In the 1970s, the preproduction stage moved to ITT Corp, Roanoke, VA, USA. While Charles worked there, he received two letters. One contained a threatening message accusing him of releasing an evil genie from its bottle; the other, from a farmer in China, asked for a means to allow him to pass a message to his distant wife to bring his lunch. Both letter writers saw a future that has since become past history.

In the 1960s, our children were small (Fig. 1). Charles often came home later than normal-dinner was waiting as were the children. I got very annoyed when this happened day after day. His words, maybe not exactly remembered, were, "Please don't be so mad. It is very exciting what we are doing; it will shake the world one day!"

I was sarcastic, "Really, so you will get the Nobel Prize, won't you!"

He was right - it has revolutionized telecommunications.

\section{THE EARLY DAYS}

In 1960 Charles joined Standard Telecommunications Laboratories Ltd. (STL), a subsidiary of ITT Corp in the UK after having worked as a graduate engineer at Standard Telephones and Cables in Woolwich for some time. Much of the work at STL was devoted to improving the capabilities of the existing communication infrastructure with a focus on the use of millimeter wave transmission systems. Millimeter waves at $35-70 \mathrm{GHz}$ could have a much higher transmission capacity. But the waters were uncharted and the challenges enormous since radio

\footnotetext{
*The 2009 Nobel Prize for Physics was shared by Charles K. Kao, Willard, S. Boyle, and George E. Smith. This paper is the text of the address given in conjunction with the award.
}

waves at such frequencies could not be beamed over long distances due to beam divergence and atmospheric absorption. The waves had to be guided by a waveguide. And in the 1950s, R\&D work on low loss circular waveguides HE-11 mode was started (Fig. 2). A trial system was deployed in the 1960s. Huge sums were invested, and more were planned, to move this system into the preproduction stage. Public expectation for new telecommunication services such as the video phone had heightened.

Charles joined the long-haul waveguide group led by Dr. Karbowiak at STL. He was excited to see an actual circular waveguide. He was assigned to look for new transmission methods for microwave and optical transmission (Fig. 3). He used both ray optics and wave theory to gain a better understanding of waveguide problems - then a novel idea. Later, his boss encouraged him to pursue a doctorate while working at STL. So Charles registered at University College London and completed the dissertation "Quasi-Optical Waveguides" in two years.

The invention of the laser in 1959 gave the telecom community a great dose of optimism that optical communication could be just around the corner. The coherent light was to be the new information carrier with capacity a hundred thousand times higher than point-topoint microwaves-based on the simple comparison of frequencies: $300 \mathrm{THz}$ for light versus $3 \mathrm{GHz}$ for microwaves.

The race between circular microwave waveguides and optical communication was on, with the odds heavily in favor of the former. In 1960, optical lasers were in their infancy, demonstrated at only a few research laborato-

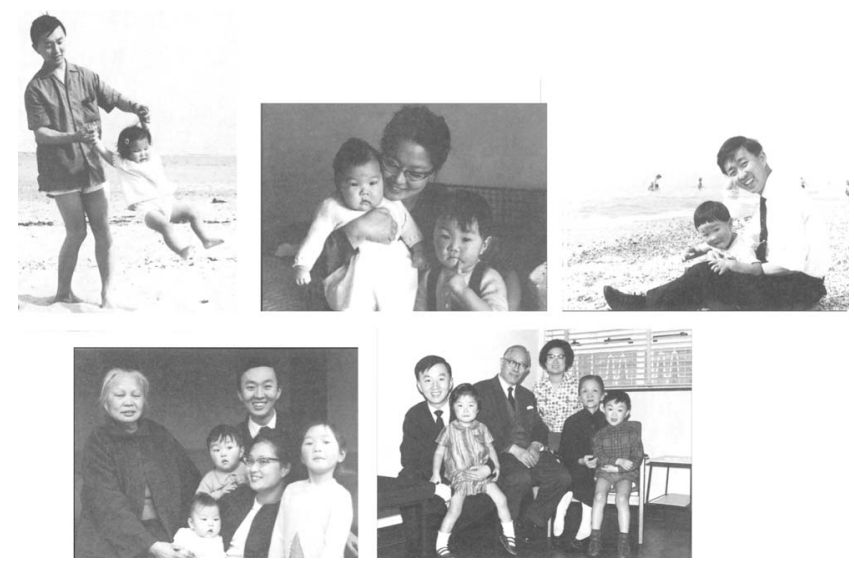

FIG. 1. The early years. 


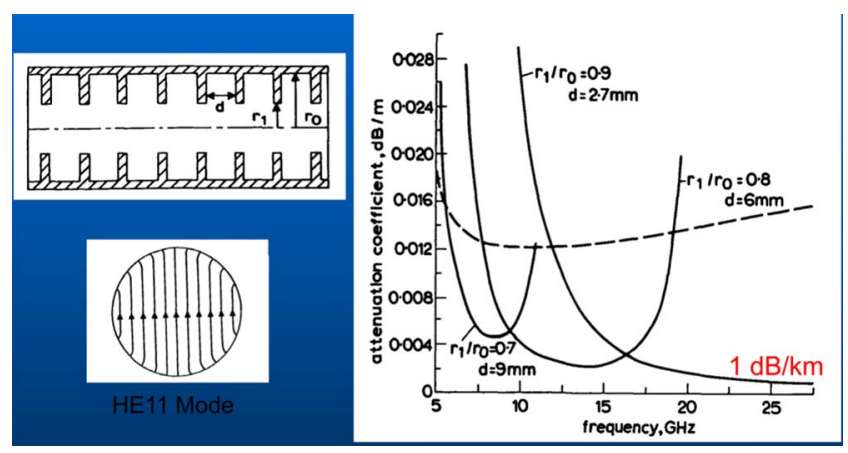

FIG. 2. (Color online) Low-loss corrugated circular waveguide.

ries and performing much below the needed specs. Optical systems seemed a nonstarter. But Charles still thought the laser had potential. He said to himself: "How can we dismiss the laser so readily? Optical communication is too good to be left on the theoretical shelf."

He asked himself the obvious questions:

(1) Is the ruby laser a suitable source for optical communication?

(2) What material has sufficiently high transparency at such wavelengths?

At that time only two groups in the world were starting to look at the transmission aspect of optical communication, while several other groups were working on solid state and semiconductor lasers. Lasers emit coherent radiation at optical frequencies, but using such radiation for communication appeared to be very difficult, if not impossible. For optical communication to fulfill its promises, many serious problems remained to be solved.

\section{THE KEY DISCOVERY}

In 1963 Charles was already involved in free space propagation experiments: the rapid progress of semiconductor and laser technology had opened up a broader scope to explore optical communication realistically. With a helium-neon laser beam directed to a spot some distance away, the STL team quickly discovered that distant laser light flickered. The beam danced around several beam diameters because of atmospheric fluctua-

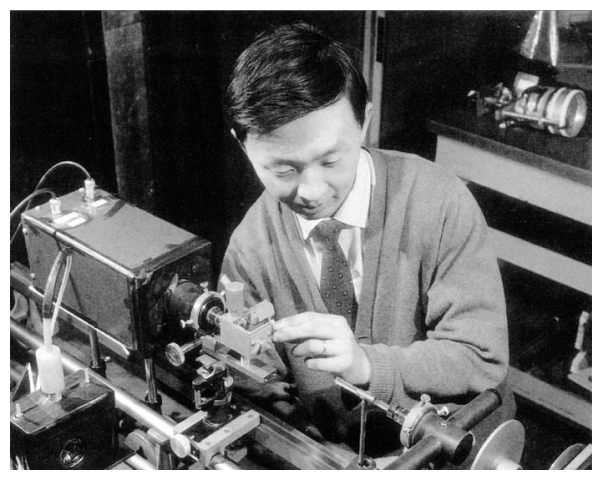

FIG. 3. The author at work. tions. The team also tried to repeat experiments done by other research laboratories around the world. For example, they set up confocal lens experiments similar to those at Bell Labs: a series of convex lenses were lined up at intervals equal to the focal length. But even at the dead of night when the air was still and even with refocusing every $100 \mathrm{~m}$, the beam refused to stay within the lens aperture. Bell Labs experiments using gas lenses were abandoned due to the difficulty of providing satisfactory insulation while maintaining the profiles of the gas lenses. These experiments were struggles in desperation to control light traveling over long distances.

At STL the thinking shifted toward dielectric waveguides. Dielectric means a nonconductor of electricity; a dielectric waveguide is a waveguide consisting of a dielectric cylinder surrounded by air. Dr. Karbowiak suggested Charles and three others to work on his idea of a thin film waveguide. But thin film waveguides failed; the confinement was not strong enough and light would escape as it negotiates a bend. When Dr. Karbowiak decided to migrate to Australia, Charles took over as the project leader and he then recommended that the team should investigate the loss mechanism of dielectric materials for optical fibers.

A small group worked on methods for measuring material loss of low-loss transparent materials. George Hockham joined him to work on the characteristics of dielectric waveguides. With his interest in waveguide theory, he focused on the tolerance requirements for an optical fiber waveguide; in particular, the dimensional tolerance and joint losses. They proceeded to systematically study the physical and waveguide requirements on glass fibers.

In addition, Charles was also pushing his colleagues in the laser group to work toward a semiconductor laser in the near infrared, with emission characteristics matching the diameter of a single-mode fiber. Single-mode fiber is an optical fiber that is designed for the transmission of a single ray or mode of light as a carrier. The laser had to be made durable and to work at room temperatures without liquid nitrogen cooling. So there were many obstacles. But in the early 1960s, esoteric research was tolerated so long as it was not too costly.

Over the next two years, the team worked toward the goals. They were all novices in the physics and chemistry of materials and in tackling new electromagnetic wave problems. But they made very credible progress in considered steps. They searched the literature, talked to experts, and collected material samples from various glass and polymer companies. They also worked on the theories, and developed measurement techniques to carry out a host of experiments. They developed an instrument to measure the spectral loss of very low-loss material, as well as one for scaled simulation experiments to measure fiber loss due to mechanical imperfections.

Charles zeroed in on glass as a possible transparent material. Glass is made from silica-sand from centuries past that is plentiful and cheap. The optical loss of transparent material is due to three mechanisms: (a) intrinsic absorption, (b) extrinsic absorption, and (c) Rayleigh 
scattering. The intrinsic loss is caused by the infrared absorption of the material structure itself, which determines the wavelength of the transparency regions. The extrinsic loss is due to impurity ions left in the material and the Rayleigh loss is due to the scattering of photons by the structural nonuniformity of the material. For most practical applications such as windows, the transparency of glass was entirely adequate, and no one had studied absorption down to such levels. After talking with many people, Charles eventually formed the following conclusions:

(1) Impurities, particularly transition elements such as iron, copper, and manganese have to be reduced to parts per million or even parts per billion. However, can impurity concentrations be reduced to such low levels?

(2) High temperature glasses are frozen rapidly and therefore are more homogeneous, leading to a lower scattering loss.

The ongoing microwave simulation experiments were also completed. The characteristics of the dielectric waveguide were fully defined in terms of its modes, its dimensional tolerance both for end-to-end mismatch, and for its diameter fluctuation along the fiber lengths. Both the theory and the simulated experiments supported the approach.

They wrote the paper entitled "Dielectric-Fibre Surface Waveguides for Optical Frequencies" and submitted it to the Proceedings of Institute of Electrical Engineers. After the usual review and revision, it appeared in July 1966-the date now regarded as the birthday of optical fiber communication.

\section{THE PAPER}

The paper started with a brief discussion of the mode properties in a fiber of circular cross section. The paper then quickly zeroed in on the material aspects, which were recognized to be the major stumbling block. At the time, the most transparent glass had a loss of $200 \mathrm{~dB} / \mathrm{km}$, which would limit transmission to about a few meters - this is very obvious to anyone who has ever peered through a thick piece of glass. Nothing can be seen.

But the paper pointed out that the intrinsic loss due to scattering could be as low as $1 \mathrm{~dB} / \mathrm{km}$, which would have allowed propagation over practical distances. The culprit is the impurities: mainly ferrous and ferric ions at these wavelengths. Quoting from the paper: "It is foreseeable that glasses with a bulk loss of about $20 \mathrm{~dB} / \mathrm{km}$ at around 0.6 micron will be obtained, as the ironimpurity concentration may be reduced to 1 part per million." In layman terms, if one has a sufficiently "clean" type of glass, one should be able to see through a slab as thick as several hundred meters. That key insight opened up the field of optical communications.

The paper considered many other issues:

- The loss can be reduced if the mode is chosen so that most of the energy is actually outside the fiber.

- The fiber should be surrounded by a cladding of lower index (which became the standard technology).

- The loss of energy due to bends in the fiber is negligible for bends larger than $1 \mathrm{~mm}$.

- The losses due to non-uniform cross sections were estimated.

- The properties of a single-mode fiber (now a key technology especially for long-distance and high data rate transmission) were analyzed. It was explained how dispersion limits bandwidth; an example was worked out for a $10 \mathrm{~km}$ route- a very bold scenario in 1966.

It may be appropriate to quote from the Conclusion of this paper:

"The realization of a successful fiber waveguide depends, at present, on the availability of suitable low-loss dielectric material. The crucial material problem appears to be one which is difficult but not impossible to solve. Certainly, the required loss figure of around $20 \mathrm{~dB} / \mathrm{km}$ is much higher than the lower limit of loss figure imposed by fundamental mechanisms."

Basically all of the predictions pointed accurately to the paths of developments and we now have 1/100 of the loss and 10000 times the bandwidth then forecastthe revolutionary proposal in the 1966 paper was in hindsight too conservative.

\section{CONVINCING THE WORLD}

The substance of the paper was presented by Dr. Kao at an IEE meeting in February 1966. Most of the world did not take notice-except for the British Post Office (BPO) and the UK Ministry of Defense, who immediately launched major research programs. By the end of 1966, three groups in the UK were studying the various issues involved: Kao himself at STL, Roberts at BPO, and Gambling at Southampton in collaboration with Williams at the Ministry of Defense Laboratory.

In the next few years, Dr. Kao traveled the globe to push his idea: to Japan, where enduring friendships were made dating from those early days, to research laboratories in Germany, in the Netherlands, and elsewhere to spread his news. He said that until more and more jumped on the bandwagon, the use of glass fibers would not take off. He had tremendous conviction in the face of widespread skepticism. The global telephony industry is huge, too large to be changed by a single person or even a single country, but he was persistent and his enthusiasm was contagious, and slowly he converted others to be believers.

The experts at first proclaimed that the materials were the most severe of the intrinsic insurmountable problems. Gambling wrote that British Telecom had been "somewhat scathing" about the proposal earlier, and Bell Labs, who could easily have led the field, simply failed to take notice until the proven technology was pointed out to them. Dr. Kao visited many glass manu- 
facturers to persuade them to produce the clear glass required. He got a response from Corning, where Maurer led the first group that later produced the glass rods and developed the techniques to make the glass fibers to the required specifications.

Meanwhile, Dr. Kao continued to pour energy into proving the feasibility of glass fibers as the medium for long-haul optical transmission. They faced a number of formidable challenges. The first was the measurement techniques for low-loss samples that were obtainable only in lengths of around $20 \mathrm{~cm}$. The problem of assuring surface perfection was also formidable. Another problem was end surface reflection loss, caused by the polishing process. They faced a measurement impasse that demanded the detection of a loss difference between two samples of less than $0.1 \%$, when the total loss of the entire $20 \mathrm{~cm}$ sample is only $0.1 \%$. An inexact measurement would be meaningless.

In 1968 and 1969, Dr. Kao and his colleagues Davies, Jones, and Wright at STL published a series of papers on the attenuation measurements of glass that addressed the above problems. At that time, the measuring instruments called spectrophotometers had a rather limited sensitivity - in the range of $43 \mathrm{~dB} / \mathrm{km}$. The measurement was very difficult: even a minute contamination could have caused a loss comparable to the attenuation itself, while surface effects could easily be ten times worse. Dr. Kao and the team assembled a homemade single-beam spectrophotometer that achieved a sensitivity of $21.7 \mathrm{~dB} / \mathrm{km}$. Later improvements with a doublebeam spectrophotometer yielded a sensitivity down to $4.3 \mathrm{~dB} / \mathrm{km}$. The reflection effect was measured with a homemade ellipsometer. To make it, they used fused quartz samples made by plasma deposition, in which the high temperature evaporated the impurity ions. With the sensitive instrument, the attenuation of a number of glass samples was measured and, eureka, the Infrasil sample from Schott Glass showed an attenuation as low as $5 \mathrm{~dB} / \mathrm{km}$ at a window around $0.85 \mu \mathrm{m}$-at last proving that the removal of impurity would lower the absorption loss to useful levels.

This was really exciting because the low-loss region is right at the gallium-arsenide laser emission band. The measurements clearly pointed the way to optical communication-compact gallium-arsenide semiconductor lasers as the source, low-cost cladded glass fibers as the transmission medium, and silicon or germanium semiconductors for detection. The dream no longer seemed remote. These measurements apparently turned the sentiments of the research community around. The race to develop the first low-loss glass fiber waveguide was on.

In 1967, at Corning, Maurer's chemist colleague Schultz helped to purify the glass. In 1968, his colleagues Keck and Zimar helped to draw the fibers. By 1970, Corning had produced a fiber waveguide with a loss of $17 \mathrm{~dB} / \mathrm{km}$ at $0.633 \mu \mathrm{m}$ using a titanium-diffused core with silica cladding, using the outside vapor deposition (OVD) method. Two years later, they reduced the loss to $4 \mathrm{~dB} / \mathrm{km}$ for a multimode fiber by replacing the titanium-doped core with a germanium-doped core. Bell Labs finally got on the bandwagon in 1969 and created a program in optical fiber research after having been skeptical for years. Their work on hollow light pipes was finally stopped in 1972. Their millimeter wave research program was wound down and eventually abandoned in 1975.

It was during this time of constant flying out to other places that this cartoon joke hit home:

"Children, the man you see at the breakfast table today is your father!"

We saw him for a few days and off he went again. Sometimes he flew off for the day for meetings at ITT Corp headquarters in New York. I would forget he had not left to go to the office and would phone his secretary to remind Charles to pick up milk or something on his way home. His secretary was very amused:

"Mrs. Kao, don't you know your husband is in New York today!"

\section{IMPACT ON THE WORLD}

Since the deployment of the first-generation, $45 \mathrm{Mbps}$ fiber-optic communication system in 1976, the transmission capacity in a single fiber has rapidly increased a millionfold to tens of terabits per second. Data can be carried over millions of $\mathrm{km}$ of fibers without going through repeaters, thanks to the invention of the optical fiber amplifier and wavelength division multiplexing. So that is how the industry grew and grew.

The world has been totally transformed because of optical fiber communication. The telephone system has been overhauled and international long distance calls have become easily affordable. Brand new megaindustries in fiber optics including cable manufacturing and equipment, optical devices, network system, and equipment have been created. Hundreds of millions of kilometers of glass fiber cables have been laid, in the ground and in the ocean, creating an intricate web of connectivity that is the foundation of the world wide web. The Internet is now more pervasive than the telephone used to be. We browse, we Skype, we blog, we go onto YouTube, we shop, we socialize online. The information revolution that started in the 1990s could not have happened without optical fibers. Over the last few years fibers are being laid all the way to our homes. All-optical networks that are environmentally green are contemplated. The revolution in optical fiber communication has not ended-it might still just be at the beginning.

\section{CONCLUSION}

The world wide communication network based on optical fibers has truly shrunk the world and brought human beings closer together. I hardly need to cite technical figures to drive this point home. The news of the Nobel Prize reached us in the middle of the night at 3 a.m. in California, through a telephone call from Stockholm (then in their morning) no doubt carried on optical fibers; congratulations came literally minutes later from 
friends in Asia (for whom it was evening), again through messages carried on optical fibers. Too much information is not always a good thing: we had to take the phone off the hook that night in order to get some sleep!

Optical communication is by now not just a technical advance, but has also caused major changes in society. The next generation will learn and grow up differently; people will relate to one another in different ways. Manufacturing of all the bits and pieces of a single product can now take place over a dozen locations around the world, providing huge opportunities for people especially in developing countries. The wide accessibility of information has obviously led to more equality and wider participation in public affairs. Many words, indeed, many books have been written about the information society, and I do not wish to add to them hereexcept to say that it is beyond the dreams of the first serious concept of optical communication in 1966 when even $1 \mathrm{GHz}$ was only a hope.

In conclusion, Charles and I want to thank the professors at The Chinese University of Hong Kong, namely, Professor Young, Professor Wong, Professor Cheung, and Professor Chen for their support in compiling this lecture for us. Charles would like to thank ITT Corp where he developed his career for 30 years and all those who climbed on to the bandwagon with him in the early days, as without the legions of believers the industry would not have evolved as it did.

Charles Kao planted the seed, Bob Maurer watered it, and John MacChesney grew its roots.

\section{REFERENCES}

See supplementary material at http://link.aps.org/ supplemental/10.1103/RevModPhys.82.2299 for a PowerPoint presentation containing 16 slides. The first slides are of descriptions of the various systems for transmission of data being researched at the time in the 1960 s-e.g., confocal and gas lens, hollow and thin film waveguides. There are then a few slides of experimental graphic data such as the fiber loss, measurements, and attenuation of the early optical fiber. The last slides give the theories and experimental result of optics, with some slides showing how the glass fiber is drawn in production and how the historical use of optical fibers has grown so swiftly worldwide in the last decade. 